\title{
BEBERAPA SIFAT HIMPUNAN KRITIS PADA PELABELAN AJAIB GRAF BANANA TREE
}

\author{
Triyani dan Irham Taufiq \\ Universitas Jenderal Soedirman \\ trianisr@yahoo.com.au
}

\begin{abstract}
A critical set in edge magic total labeling $\lambda$ on graph $G$ is a subset label such that it can forms the edge magic total labeling uniquely. This paper investigate critical set on Banana Tree graph. The result shows some properties of critical set on Banana Tree graph, such as the size of it at least $(n-1) k$, where $n$ is number of leaf and $k$ is number of star, except the size of critical set on graph $B T(1,1)$ is 2 . Beside it, if $x$ is the label of any leaf and $y$ is the label of the edge adjacent to it then each critical set in $\lambda$ must contain either $x$ or $y$, not both.
\end{abstract}

Keywords : properties of critical set, edge magic total labeling, Banana Tree graph.

\begin{abstract}
ABSTRAK. Sebuah himpunan kritis pada pelabelan total sisi ajaib $\lambda$ pada graf $G$ merupakan subhimpunan label sedemikian sehingga label tersebut membangun pelabelan total sisi-ajaib $\lambda$ secara tunggal. Pada artikel ini diselidiki semua kemungkinan himpunan kritis pada pelabelan total sisi ajaib graf Banana Tree. Hasil penelitian menunjukkan bahwa terdapat beberapa sifat himpunan kritis pada graf Banana Tree, yaitu minimal berukuran $(n-1) k$, dengan $n$ menyatakan banyaknya daun dari graf bintang dan $k$ menyatakan banyaknya graf bintang kecuali himpunan kritis pada graf $B T(1,1)$ berukuran 2. Selain itu, jika $x$ adalah label dari titik daun dan $y$ adalah label dari sisi yang bersisian dengan $x$, maka setiap himpunan kritis dalam $\lambda$ harus memuat $x$ atau $y$, tapi tidak keduanya.
\end{abstract}

Kata Kunci : Karakteristik himpunan kritis, pelabelan total sisi ajaib, graf Banana Tree

\section{PENDAHULUAN}

Sebuah himpunan kritis pada pelabelan suatu graf adalah subhimpunan label dan posisi label tersebut yang apabila dilengkapi akan menghasilkan pelabelan graf secara tunggal (Imron dkk., 2007). Salah satu konsep dari himpunan kritis yaitu penentuan suatu garis pada bidang datar (Sudarsana dan Junaidi, 2008). Penentuan sebuah garis pada bidang datar membutuhkan paling sedikit dua buah titik sebagai dasar untuk mengetahui kemiringannya. Jika hanya 
diberikan sebuah titik maka ada tak hingga banyak kemungkinan persamaan garis yang dapat dibuat.

Menurut Baskoro (2007), masalah menentukan himpunan kritis dari suatu pelabelan graf merupakan masalah yang tidak mudah karena kemungkinan dari subhimpunan label pada graf tersebut sangat banyak, kemudian masing-masing subhimpunan tersebut dicari subhimpunan label yang dapat membangun pelabelan graf secara tunggal.

Salah satu jenis dari pelabelan graf adalah pelabelan total sisi ajaib. Pelabelan total sisi ajaib pada graf $G$ adalah fungsi bijektif yang memetakan setiap titik dan sisi ke bilangan bulat positif sedemikian sehingga jumlah label dua buah titik dan sebuah sisi yang bersisian dengan kedua titik tersebut adalah sama. Graf yang dapat dilabeli dengan pelabelan total sisi ajaib selanjutnya disebut graf sisi ajaib.

Beberapa kajian tentang himpunan kritis pada pelabelan total sisi ajaib telah dilakukan antara lain: himpunan kritis dalam pelabelan total sisi ajaib pada graf Star (Baskoro, 2005) dan himpunan kritis dalam pelabelan total sisi ajaib pada graf Caterpilar (Imron dkk., 2007).

Pada artikel ini akan dibahas tentang sifat-sifat himpunan kritis pada pelabelan total sisi ajaib graf Banana Tree. Graf Banana Tree adalah graf pohon yang dibentuk dari gabungan terpisah graf bintang dengan menambahkan sebuah titik baru yang terhubung dengan sebuah titik daun dari setiap graf bintang.

Adapun sistematika penulisan artikel ini adalah bagian pertama pendahuluan yang menguraikan latar belakang masalah, rumusan masalah, beberapa hasil kajian yang telah dilakukan dan tujuan penulisan. Bagian ke dua membahas himpunan titik dan sisi pada graf Banana Tree yang meliputi pendefinisian dan kardinalitas himpunan titik dan sisi pada graf Banana Tree. Pada bagian ke tiga membahas pelabelan total sisi ajaib graf Banana Tree yang menguraikan lemma dan teorema yang digunakan dalam penulisan artikel. Bagian ke empat membahas beberapa sifat himpunan kritis pada pelabelan graf Banana Tree. Bagian ke lima pada artikel ini adalah kesimpulan yang menguraikan simpulan dari bagian sebelumnya. 


\section{HIMPUNAN TITIK DAN SISI PADA GRAF BANANA TREE}

Graf Banana Tree dinotasikan dengan $B T\left(n_{1}, n_{2}, \ldots, n_{k}\right)$ merupakan graf pohon yang terdiri dari gabungan terpisah graf bintang dengan menambahkan sebuah titik yang terhubung dengan sebuah titik daun dari setiap graf bintang. Notasi $n_{i}$ menyatakan banyaknya titik daun dari graf bintang ke- $i$ dan $k$ menyatakan banyaknya graf bintang.

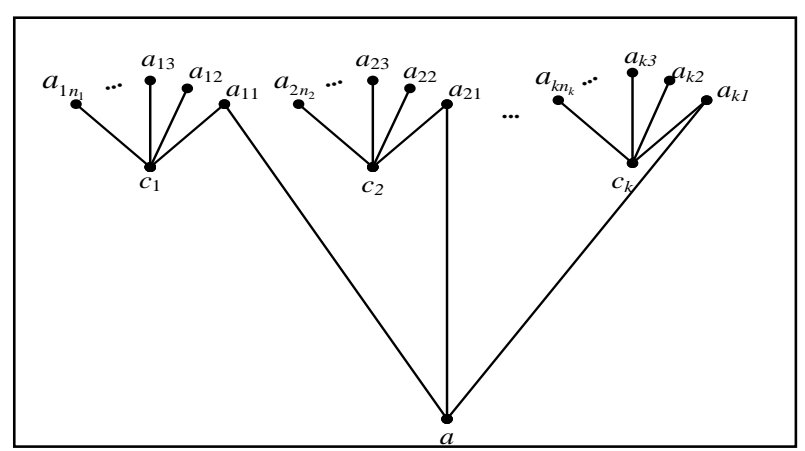

Gambar 1. Graf Banana Tree

Himpunan titik pada graf Banana Tree $B T\left(n_{1}, n_{2}, \ldots, n_{k}\right)$ didefinisikan dengan $V\left(B T\left(n_{1}, n_{2}, \ldots, n_{k}\right)\right)=\{a\} \cup\left\{c_{i} \mid 1 \leq i \leq k\right\} \cup\left\{a_{i j} \mid 1 \leq i \leq k ; 1 \leq j \leq n_{i}\right\}, \quad$ dan himpunan sisinya didefinisikan dengan

$E\left(B T\left(n_{1}, n_{2}, \ldots, n_{k}\right)\right)=\left\{a a_{i 1} \mid 1 \leq i \leq k\right\} \cup\left\{c_{i} a_{i j} \mid 1 \leq i \leq k ; 1 \leq j \leq n_{i}\right\}$. Notasi $c_{i}$ menyatakan titik pusat pada graf bintang ke- $i$, a menyatakan sebuah titik baru, dan $a_{i j}$ menyatakan titik daun ke-j pada graf bintang ke- $i$. Banyaknya titik pada $B T\left(n_{1}, n_{2}, \ldots, n_{k}\right)$ adalah sebuah titik ditambah dengan banyaknya titik dari setiap graf bintang. Jika graf bintang ke-i dinotasikan sebagai $S_{n_{i}}$, maka banyaknya titik pada graf Banana Tree adalah

$$
\begin{aligned}
\left|V\left(B T\left(n_{1}, n_{2}, \ldots, n_{k}\right)\right)\right| & =1+\left|V\left(S_{n_{1}}\right)\right|+\left|V\left(S_{n_{2}}\right)\right|+\ldots+\left|V\left(S_{n_{k}}\right)\right| \\
& =1+\sum_{i=1}^{k}\left(n_{i}+1\right) \\
& =1+k+\sum_{i=1}^{k} n_{i} .
\end{aligned}
$$


Karena graf Banana Tree merupakan graf pohon, maka banyaknya sisi pada graf Banana Tree adalah

$$
\begin{aligned}
\left|E\left(B T\left(n_{1}, n_{2}, \ldots, n_{k}\right)\right)\right| & =\left|V\left(B T\left(n_{1}, n_{2}, \ldots, n_{k}\right)\right)\right|-1 \\
& =k+\sum_{i=1}^{k} n_{i} .
\end{aligned}
$$

Akibatnya, banyaknya bilangan positif yang dibutuhkan untuk melabeli titik dan sisi pada graf Banana Tree $B T\left(n_{1}, n_{2}, \ldots, n_{k}\right)$ adalah

$$
\begin{aligned}
\left|V\left(B T\left(n_{1}, n_{2}, \ldots, n_{k}\right)\right)\right|+\left|E\left(B T\left(n_{1}, n_{2}, \ldots, n_{k}\right)\right)\right| & =1+k+\sum_{i=1}^{k} n_{i}+k+\sum_{i=1}^{k} n_{i} \\
& =1+2\left(k+\sum_{i=1}^{k} n_{i}\right)
\end{aligned}
$$

\section{PELABELAN TOTAL SISI AJAIB PADA GRAF BANANA TREE}

Bentuk khusus dari pelabelan total sisi ajaib adalah pelabelan super total sisi ajaib, yaitu pelabelan total sisi ajaib yang label titiknya adalah bilangan positif terurut $1,2, \ldots,|V(G)|$. Lemma berikut dapat digunakan sebagai acuan dalam menentukan sifat dalam himpunan kritis pada pelabelan graf.

Lemma 3.1 (Figueroa-Centeno dkk., 2001). Sebuah graf $G$ dengan $|V(G)|$ menyatakan banyaknya titik pada graf $\mathrm{G}$ dan $|E(G)|$ menyatakan banyaknya sisi pada graf $G$ adalah graf super total sisi ajaib jika dan hanya jika terdapat fungsi bijektif $\lambda: V(G) \rightarrow\{1,2, \ldots,|V(G)|\}$ sedemikian sehingga $S=\{\lambda(x)+\lambda(y) \mid x y \in E(G)\}$ adalah sebuah himpunan yang terdiri dari bilangan bulat berturutan. Selanjutnya, $\lambda$ disebut pelabelan super total sisi ajaib dari graf $G$ dengan konstanta ajaib $h=|V(G)|+|E(G)|+s$ dengan $s=\min \{z \mid z \in S\}$ dan

$$
\begin{aligned}
S & =\{\lambda(x)+\lambda(y) \mid x y \in E(G)\} \\
& =\{h-(|V(G)|+1), h-(|V(G)|+2), \ldots, h-(|V(G)|+|E(G)|)\} .
\end{aligned}
$$


Teorema 3.2. (Hussain, dkk., 2009). $G \cong B T\left(n_{1}, n_{2}, \ldots, n_{k}\right)$ dikatakan graf super total sisi ajaib jika $n_{1}=n_{2}=\ldots=n_{k}=n$ dan $\left\lceil\frac{k}{2}\right\rceil \leq n \leq k-1$.

\section{BEBERAPA SIFAT HIMPUNAN KRITIS PADA PELABELAN AJAIB GRAF BANANA TREE}

Menurut Imron dkk (2007), Sebuah himpunan kritis pada pelabelan suatu graf adalah subhimpunan label dan posisi label tersebut yang jika dilengkapi akan menghasilkan pelabelan tersebut secara tunggal. Secara sederhana jika diberikan subhimpunan label suatu graf dan posisinya, apakah himpunan tersebut hanya membangun graf yang sama dengan pelabelannya secara tunggal? Jika ya maka himpunan tersebut adalah himpunan kritis.

Sebelum menguraikan sifat himpunan kritis pada graf $B T\left(n_{1}, n_{2}, \ldots, n_{k}\right)$, berikut diberikan contoh label posisi (gambar 2a) dan pelabelan graf total sisi ajaib $\lambda$ pada graf $B T(1,1)$ (gambar $2 b$ ). Himpunan pasangan terurut dari label posisi dan pelabelan total sisi ajaib pada graf $B T(1,1)$ dapat ditulis sebagai $\{(1,4),(2,8),(3,1),(4,9),(5,3),(6,7),(7,2),(8,6),(9,5)\}$. Setiap satu elemen dari himpunan pasangan terurut ini bukan merupakan himpunan kritis, sebab jika dipunyai hanya sebuah pasangan terurut ini, selalu dapat dikonstruksi pelabelan super total sisi ajaib lain yaitu dengan menukar label titik daun dengan label sisi daun yang bersisian dengan titik tersebut. Akan tetapi jika dipunyai dua elemen yang merupakan kombinasi dari 9 pasangan terurut, misal $(5,3)$ dan $(9,5)$, maka tidak dapat dikonstruksi pelabelan lain selain pelabelan $\lambda$. Hal ini berarti subhimpunan pasangan terurut $\{(5,3),(9,5)\}$ merupakan himpunan kritis minimal. Beberapa himpunan kritis minimal pada graf $B T(1,1)$ yang lain adalah $\{(5,3),(8,6)\}$, dan $\{(4,9),(9,5)\}$. Subhimpunan $\{(5,3),(1,4)\}$ bukan himpunan kritis. Karena dengan menukar $(8,6)$ dengan $(8,5)$ dan $(9,5)$ dengan $(9,6)$, dapat dikonstruksi pelabelan total sisi ajaib lain selain pelabelan total sisi ajaib $\lambda$ yaitu sebuah himpunan pasangan terurut dari label posisi dan pelabelan total sisi ajaib 
baru $\{(1,4),(2,8),(3,1),(4,9),(5,3),(6,7),(7,2),(8,5),(9,6)\}$. Jadi himpunan kritis minimal pada graf $B T(1,1)$ minimal anggotanya sebanyak 2 .

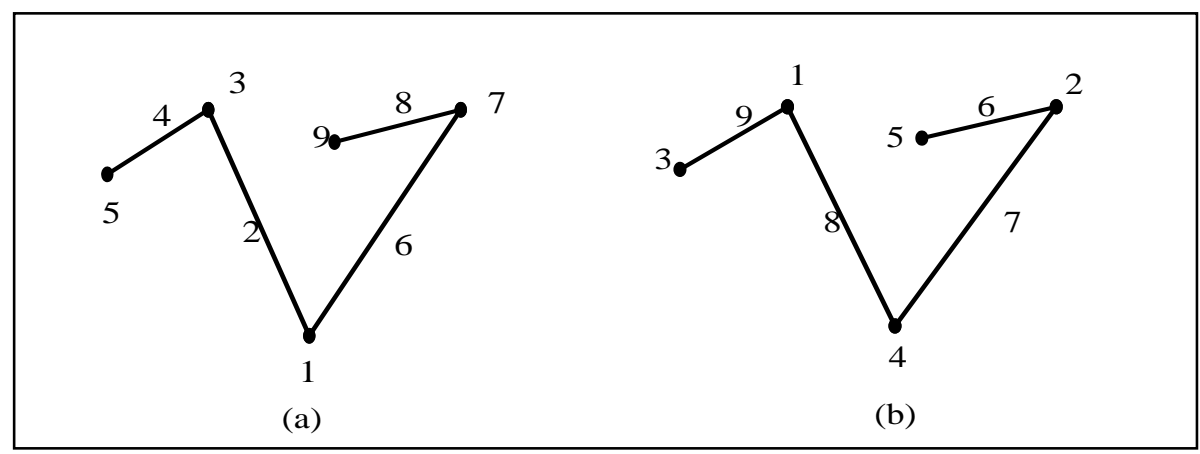

Gambar 2. Label posisi dan pelabelan total sisi ajaib pada graf $B T(1,1)$

Berdasarkan hal ini, diperoleh beberapa sifat himpunan kritis dalam pelabelan total sisi ajaib pada graf $B T\left(n_{1}, n_{2}, \ldots, n_{k}\right)$ sebagai berikut:

Sifat 1. Himpunan kritis pada graf Banana Tree $B T\left(n_{1}, n_{2}, \ldots, n_{k}\right)$ dengan $n_{1}=n_{2}=\ldots=n_{k}=n, n \geq 2, k \geq 2$ minimal anggotanya sebanyak $(n-1) k$ dengan $n$ menyatakan banyaknya titik daun dari graf bintang dan $k$ menyatakan banyaknya graf bintang.

Bukti: Misal $\lambda$ menyatakan pelabelan total sisi ajaib pada graf $B T\left(n_{1}, n_{2}, \ldots, n_{k}\right)$, dan $Q_{\lambda}$ adalah himpunan kritis pada pelabelan $\lambda$. Andaikan $\left|Q_{\lambda}\right|<(n-1) k$ artinya banyaknya elemen dalam $Q_{\lambda}$ kurang dari banyaknya titik daun pada graf $B T\left(n_{1}, n_{2}, \ldots, n_{k}\right)$. Akibatnya terdapat $i$ dan $j$ sedemikian hingga pasangan terurut $\left(c, x_{i j}\right)$ dan $\left(d, y_{i j}\right)$ dengan $c, d$ menyatakan label posisi dan $x_{i j}, y_{i j}$ masing-masing menyatakan label titik daun dan label sisi daun yang bersisian dengan titik tersebut, keduanya tidak berada di $Q_{\lambda}$. Oleh karena itu, pelabelan total sisi ajaib yang dapat dikonstruksi dari $Q_{\lambda}$ tidak tunggal, yaitu dengan menukar pasangan terurut $\left(c, x_{i j}\right)$ dengan $\left(c, y_{i j}\right)$ dan $\left(d, y_{i j}\right)$ dengan $\left(d, x_{i j}\right)$. Hal ini kontradiksi dengan definisi himpunan kritis. Oleh karena itu, haruslah $\left|Q_{\lambda}\right| \geq(n-1) k$. 
Sifat 2. Jika $x$ adalah label dari titik daun $v$ dan $y$ adalah label dari sisi yang bersisian dengan $v$, maka setiap himpunan kritis dalam $\lambda$ harus memuat $x$ atau $y$, tapi tidak keduanya.

Bukti: Misalkan $\left\{a_{12}, a_{13}, \ldots, a_{k n}\right\}$ adalah himpunan semua titik daun dari graf Banana Tree $B T\left(n_{1}, n_{2}, \ldots, n_{k}\right)$ dan $\left\{e_{12}, e_{13}, \ldots, e_{k n}\right\}$ adalah himpunan semua sisi yang bersisian dengan titik daun. Misal $\lambda\left(a_{i j}\right)=x_{i j}$ menyatakan label titik daun dan $\lambda\left(e_{i j}\right)=y_{i j}$ menyatakan label sisi daun yang bersisian dengan titik daun $a_{i j}$, dengan $i=1,2, \ldots, k$ dan $j=2,3, \ldots, n$, sehingga $\left(a, x_{i j}\right)$ menyatakan label $x_{i j}$ pada posisi $a$, dan $\left(b, y_{i j}\right)$ menyatakan label $y_{i j}$ pada posisi $b$. Akan ditunjukkan bahwa setiap himpunan kritis dalam pelabelan $\lambda$ harus memuat memuat $\left(a, x_{i j}\right)$ atau $\left(b, y_{i j}\right)$, tapi tidak keduanya. Andaikan terdapat himpunan kritis yang memuat $\left(a, x_{i j}\right)$ dan $\left(b, y_{i j}\right)$. Berdasarkan sifat 1 maka terdapat sedikitnya sebuah titik $v$ dan sisi daun yang bersisian dengan $v$ yang tidak termuat di $Q_{\lambda}$. Dengan kata lain terdapat $s$ dan $t$, sedemikian hingga $\left(c, x_{s t}\right)$ dan $\left(d, y_{s t}\right)$ keduanya tidak berada di himpunan kritis $Q_{\lambda}$. Oleh karena itu, dapat dikonstruksi pelabelan total sisi ajaib $\lambda$ ' dengan cara menukar pasangan terurut $\left(c, x_{s t}\right)$ dengan $\left(c, y_{s t}\right)$ dan $\left(d, y_{s t}\right)$ dengan $\left(d, x_{s t}\right)$. Akibatnya pelabelan total sisi ajaib yang dapat dikonstruksi dari $Q_{\lambda}$ tidak tunggal. Hal ini kontradiksi dengan definisi himpunan kritis. Oleh karena itu, haruslah setiap himpunan kritis dalam pelabelan $\lambda$ memuat $\left(a, x_{i j}\right)$ atau $\left(b, y_{i j}\right)$, tapi tidak keduanya.

\section{KESIMPULAN}

Berdasarkan penentuan himpunan kritis, diperoleh sifat banyaknya anggota minimal dari himpunan kritis pada pelabelan total sisi ajaib graf $B T\left(n_{1}, n_{2}, \ldots, n_{k}\right)$ adalah $(n-1) k$ dengan $n$ menyatakan banyaknya titik daun dari graf bintang dan $k$ menyatakan banyaknya graf bintang, kecuali himpunan kritis pada graf $B T(1,1)$, banyaknya anggota minimal adalah 2 . Setiap himpunan kritis 
dalam pelabelan total sisi ajaib pada graf $B T\left(n_{1}, n_{2}, \ldots, n_{k}\right)$ tidak memuat label titik daun sekaligus label sisi daun yang bersisian dengan titik tersebut, tetapi harus salah satu, yaitu memuat label titik daun atau label sisi daun yang bersisian dengan titik tersebut.

\section{DAFTAR PUSTAKA}

Baskoro, E. T. 2005. Critical Sets in Edge-Magic Total Labellings, Journal of Combinatorial Mathematics and Combinatorial Computing, 55(1), 33-42.

Baskoro, E. T. 2007. Mengenalkan Indonesia Melalui Teori Graf. Pidato Ilmiah Guru Besar ITB. Bandung.

Figueroa-Centeno, R. M., Ichisima, R., dan Muntaner-Batle, F. A 2001. The place of super edge-magic labeling among other classes of labeling, Discreate Math. 231, 153-168.

Hussain, M., Baskoro, E. T., dan Slamin. 2009. On super edge-magic total labeling of Banana Trees. Utilitas Math., Vol 79, 243-251.

Imron, C., Setiyono, B., Simanjuntak, R., dan Baskoro, E. T. 2007. Critical Set of Caterpillar Graph for Secret Sharing Scheme, Proceeding IGGTIS, ITB-Bandung, 10-15.

Sudarsana, I. W. dan Junaidi. 2008. Secret Sharing Scheme Based on Magic Labeling of Star, Proceeding of International Converence and Workshop on Basic and Aplied Science (ICOWOBAS). UNAIR-Surabaya, 244-249. 